\title{
The Implementation of Kit Built Concept Mapping To Help Non-English Department Students Improve Their Reading Skills
}

\author{
Atiqah Nurul Asri,atiqah.nurul@polinema.ac.id, Politeknik Negeri Malang, Malang, \\ Indonesia \\ Banni Satria Andoko, ando@polinema.ac.id, Politeknik Negeri Malang, Malang, \\ Indonesia
}

\begin{abstract}
Reading skill is important, especially for non-English departments students like those of the Information Technology Department at State Polytechnic of Malang. However, based on the observation and the results of the tests, the students showed low performance and motivation in reading English written texts even though the texts were on IT related subjects. Therefore, the students were introduced to Kit-Built Concept Mapping to help them overcome the problems. This study is Classroom Action Research (CAR) to analyze the implementation of the method to help the students improve their reading skills as well as motivation to read. There were some procedures they had to follow and some tests to do in this study. This study was said to be successful and stopped when the students' scores met the criteria of success previously determined, namely, more than $50 \%$ of them had the average score of more than 66 or B following the State Polytechnic of Malang Academic Handbook. After the first and second cycles, the average scores obtained showed improvement both in the first and second cycles. Hence, even though the students' Reading Comprehension scores were improved, after the paired t-test analyzed the two average scores, it was found that there was no significant difference between them. Accordingly, it can be said that this method was not fully successful in improving the students' reading skills even though the questionnaire and interview showed the students' interests and motivation to read English written texts more than before.

Keywords: Kit Built Concept Mapping, reading skills, reading comprehension
\end{abstract}

\section{INTRODUCTION}

In learning foreign languages, reading is an ability that should also be well-mastered. Yet, learners often experience many difficulties in understanding an English text. This is because, as the explanation about reading above, the learner must be able to capture the idea or message that the writer wants to convey or understand the contents of the text. In fact, in their academic life, students, especially those who study at the Information Technology Department often time are required to read English written textbooks, modules, or articles. It is not uncommon for lecturers, both English and IT courses lecturers, to provide the students with e-books or other texts in English to read since most IT-related theories are written in that language. Besides, when starting to submit a Final Report or Thesis proposal, one of the texts that must be included in the reference list is a journal article related to the topic to be appointed and most of them are English written articles. Thus, many students complain that they feel they have no ability in English so they are reluctant to read it. 
To overcome those problems, in fact, English teachers of this department, in teaching students the ability to read, have already implemented several strategies including scanning, skimming, brainstorming, and KWL techniques (Know, Want to know, and Learn) as prereading activities to connect the knowledge, information, and previous experience that students have with the text to be read. Besides, in a while reading activities, the teachers have also implemented several strategies, such as Stop-and-Think where they ask students to read the text then stop to give questions, discuss key ideas, difficult words, or ask for experience or knowledge related to the text and resume the rest of the text. As for post-reading activities, the teachers also provide exercises to evaluate their understanding, ask them to make summaries, complete tables, make charts, and so on.

In addition to these strategies, the teachers also update the texts used on the modules by searching for the latest to get the students' interests as well. Nevertheless, based on other observations made, the students still have difficulties in understanding them. This should not happen because the texts in the modules are those related to their main course, namely related to the Information Technology field. They should be able to relate their previous knowledge to understand the contents of the text being read. What happened is that they are reluctant even to try to understand them just because they are written in English, before reading it.

However, English courses themselves are only given in semesters 1, 2, and 8 for D4 Informatics Engineering Study Program students, and 1, 3 and 5 for D3Informatics Management Study Program students (following 2016 Curriculum). Whereas in the previous curriculum, it was given in semesters 2,4 , and 5 for those two study program students, with a $3 \times 45$-minute lecture per week. This also causes the teachers to feel difficult to maintain the students' ability and habits of reading or improve their abilities due to the limitations of the time allotted for the course.

For this reason, an effort was proposed to assist students in understanding English texts while at the same time enhancing their reading skills and motivation as well as making reading as a fun activity. One method that was tried to be implemented was the Kit-Built Concept Mapping method. This method is the development of the Concept Mapping method, which is a learning strategy that can be used to improve students' learning skills independently and help them become independent learners (Tajeddin \& Tabatabaei, 2016). Besides, this is a visual form of knowledge that has meaning for learners because it shows the relationship between several concepts depicted hierarchically. Concept Mapping is a graphic media that activates and describes previous knowledge that can help solve problems, foster the ability to think and understand conceptually and regulate and memorize knowledge (Zwaal \& Otting, 2012).

Moreover. It can also be used as cognitive tools to help learners manage their knowledge and learning experiences and increase their self-awareness through reflective thinking. The map consists of vertices containing concepts or items, usually surrounded by circles or squares and connecting lines that show the relationship between the two. Words written on a connecting line are called conjunctions that connect words or connect phrases that determine the relationship between two concepts.

From the understanding of Concept Mapping above, then Alkhateeb et al.(2016) developed Kit-Built Mapping, which is a framework to realize automatic diagnosis of concept maps built by students and provide feedback on their mistakes on the map. Besides, Andoko, Hayashi, and Hirashima mention that Kit-Built Mapping (KB-Mapping) is an application that can be used for learning adopted from concept maps and expanded into a new form. There are three stages in applying the KB-Mapping method according to them, namely the creation of goal maps (by teachers), learner 's map (by learners), and Kit-Built Analyzer. Goal map is the stage where the teacher makes a goal map which is then separated into a circle and connecting 
lines that the learner will later recreate in the next stage. So, the learner's map is created by learners by completing the circle and connecting lines provided by the teachers and they are not allowed to make, update, or delete existing circles or connecting lines. Both goal maps and learner maps are created using the help of web-based applications. The third stage is the stage where the teacher evaluates by comparing the map he made (goal map) with the map made by students (learner's map).

Alkhateeb et al. (2016) developed this method based on their interpretation of the understanding of Reading Comprehension which was concluded from a combination of comprehension notions in Oxford and Cambridge dictionaries. Reading Comprehension (RC) according to them, is the ability of learners to fully understand and memorize important information included in the text they read. RC is also defined as the level of understanding of text/message. This understanding comes from the interaction between written words and how those words trigger knowledge outside the text/message. Their other argument is that many studies use memory recalling as indicators to measure the level of understanding, and they also use delayed comprehension tests to find out the depth of learners' understanding of the texts they read. So in their research, they applied the Kit-Built Concept Mapping method by using well-prepared text for learners to read, asking the learners to create a map (learner's map) to evaluate whether it was following the goal's map made by the teacher. After that, the learner was given questions about the text being read to measure their understanding. Then two weeks later, the learners were given a test of the same text. The results of their research turned out that the learners could still do the test well and remember the information contained in the text that was read two weeks earlier. This is because knowledge in memory is stored in a structured form that determines the ability to maintain, remember, and use it to solve problems.

Table 1. The Procedure of the Implementation of Kit-Built Concept Mapping by Alkhateeb et al. (2016).

\begin{tabular}{|c|c|l|}
\hline Meeting & Time (in minutes) & Students' Activities \\
\hline \multirow{3}{*}{1} & 10 & Reading a given text \\
\cline { 2 - 3 } & 10 & Making a map in the application (may read the text) \\
\cline { 2 - 3 } & 5 & Doingthe Reading Comprehension Test \\
\hline 2 & 5 & Doing Delay test: re-doing Reading Comprehension Test \\
\hline
\end{tabular}

Based on the background above, this research was carried out by applying the KitBuilt Concept Mapping method (henceforth, KB-Mapping) to help improve the reading skills of Information Technology Department students as well as their motivation in reading English texts. The method is implemented with the help of an application that can be accessed online. The research was Class Action Research with the research subjects were students of the 4th semester of the 2017/2018 academic year who are taking the English for Informatics 2course. The students were assumed to be more motivated and engaged since most of the reading activities were done with the help of the computer and the internet connection, just like most of their classes in this department. Yet, unlike the previous study conducted by Alkhateeb, et al. (2016), the students were given the delay test the week after due to the time limitation in conducting the study and the time in doing all the processes were added (see Table 2) due to the possibility of the slow internet connection. In conclusion, this article is aimed at describing the implementation of KB-Mapping to help the non-English department students improve their reading skills and motivation, as well as finding out their perception about its implementation. 


\section{METHOD}

This study was Classroom Action Research (CAR), which was first introduced by Kemmis and McTaggart (1992). The subjects in this study were the 4th-semester students of the Information Technology Department of State Polytechnic Malang, academic year 2017/2018 who were taking English for Informatics 2 course, specifically class TI-2D.

In this study, there are five kinds of research instruments designed for data collection, namely:

1. teacher's observation checklist to guide the teacher in applying this method in each meeting.

2. The teacher's field notes to record what is happening during the KB-Mapping implementation and is used as self-reflection at each planned meeting.

3. Reading comprehension tests based on the given texts to read and map.

4. the scoring rubric used as a criterion of success of the implementation of KB-mapping, taken from the score of the conversion of values in the 2016/2017 State Polytechnic of Malang Academic Book. This study is said to be successful if more than $50 \%$ of research subjects can obtain a minimum score of 66 or at least B in the Reading Comprehension test given.

5. The questionnaire, consisting of 8 questions with Likert Scale and one open question regarding students' perceptions of the implementation of KB-Mapping in improving their reading comprehension skills.

This study had two cycles, and each consisted of 2 meetings. There were four stages, namely: planning, implementation, observation, and reflection or evaluation stage. Moreover, the second cycle was conducted the week after the second meeting of the first cycle.

In the planning stage, the researcher planned this study consisting of two cycles, each of which consisted of 2-3 meetings. Besides, she also studied all menus on the web application at http://kit-build.net:3900/system/analyzer/main.html designed and made by Banni Satria Andoko. Next, the Lesson Plan for three meetings and reading texts used for this study were carefully made and chosen. The prepared texts were taken from several texts in various books about teaching English for Informatics or Computer Science which were tailored to the abilities of students. Besides, Reading Comprehension Tests following the selected text and one for pre-test before KB-Mapping was applied to determine the student's initial score or ability were also designed. Because this study was Class Action Research and applied a method, to measure the success (criteria of success) of the implementation of KB-Mapping required Scoring Rubric taken from the list of values and conversions contained in the 2016/2017 State Polytechnic of Malang Academic Book. For this reason, it was determined that this study would be said to meet these criteria if more than $50 \%$ of students succeeded in at least gaining a score of 66 in the Reading Comprehension test. In addition to that, the researcher also made a questionnaire to determine students' perceptions of the implementation of this method to help improve their reading skills.

In the implementation stage, at the first meeting, the researcher, who was also a teacher in the class, provided a Reading Comprehension pre-test for approximately 20 minutes to measure the students' initial ability before the KB-Mapping method was applied. After that, students were introduced to the method and asked to access the web http://kitbuild.net:3900/system/editor/main.html and learn about the features. The researcher also gave a simple example of making KB-Mapping and asked the students to practice it. Next, the researcher explained the research objectives and the criteria for success. At the second meeting, initially, the researcher did pre-reading activities, asking questions related to the text 
and igniting students' prior knowledge about the topic to be discussed, as well as discussing difficult words found in the text.

Furthermore, the research procedures (see Table 2) were at; first, the students were asked to read the prepared text for 10 minutes, then made a map based on the text they read. Making this map was limited to only 20 minutes. After that, they were given a Reading Comprehension test. The results of this test were analyzed whether they had met the criteria of success or not. If not, the researcher would revise and repeat the research procedures.

Table 2. The research procedures

\begin{tabular}{|c|c|l|}
\hline Meeting & Time (in minutes) & Students' Activities \\
\hline \multirow{3}{*}{1} & 10 & Reading a given text \\
\cline { 2 - 3 } & 20 & Making a map in the application (may read the text) \\
\cline { 2 - 3 } 2 & 10 & $\begin{array}{l}\text { Doing the Reading Comprehension Test } \\
\text { week after) }\end{array}$ \\
\hline
\end{tabular}

In the observation stage, during the implementation of the method, the researcher also conducted observations about the implementation of KB-Mapping by filling out research instruments in the form of a teacher's observation checklist and teacher's field notes. At the end of the first cycle, the students were given a questionnaire to fill out.

In the final stage, the reflection stage, data from all instruments were analyzed and concluded. When it met the pre-determined criteria of success, the research would end, and the results became the research conclusions. If it did not meet, then the researcher would revise following the deficiencies found and repeat the research cycle.

\section{RESULT}

In the first cycle, the first meeting, the students have explained Concept Mapping and were asked to open the application at http://kit-build.net:3012 as in Figure 1 to see the menu and try to make KB-Mapping. Previously, they were given an account as prepared beforehand. They were also informed about the procedures of the methods and asked to try the application and given the text that had been learned in the previous meeting to make the map by connecting one node to the other, as shown in Figure 2 and Figure 3. The text was deliberately chosen to shorten the time. Then, after the time of making the map was complete, then the students were asked to work on reading comprehension questions and the results were calculated and made as a pre-test score. The average of the pre-test score was 80.76 .

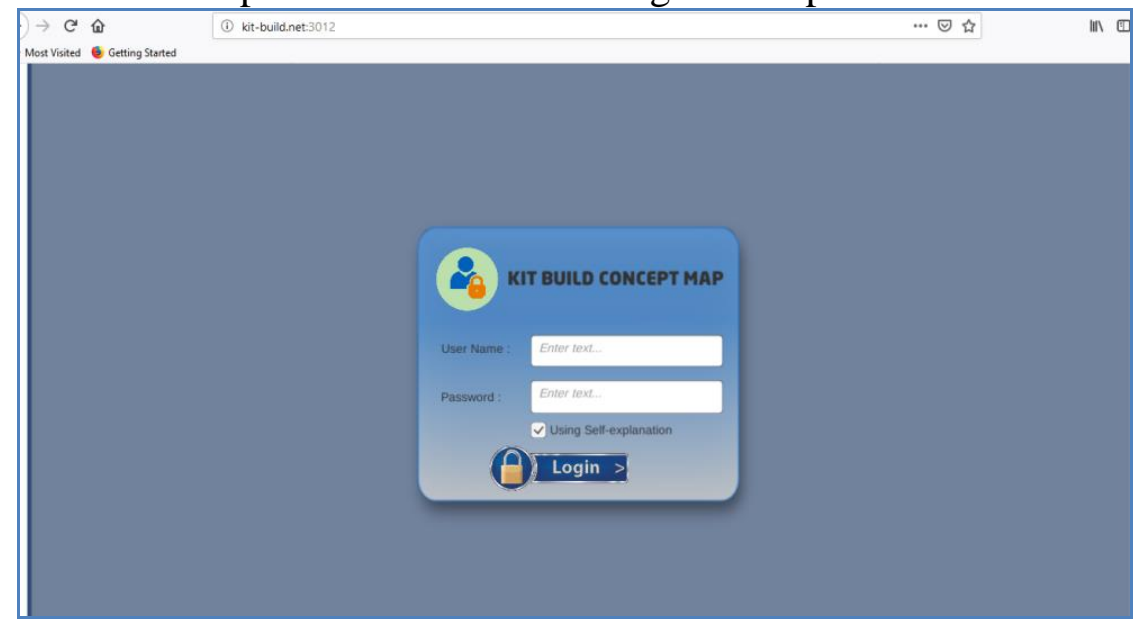

Figure 1. The Interface of the application 


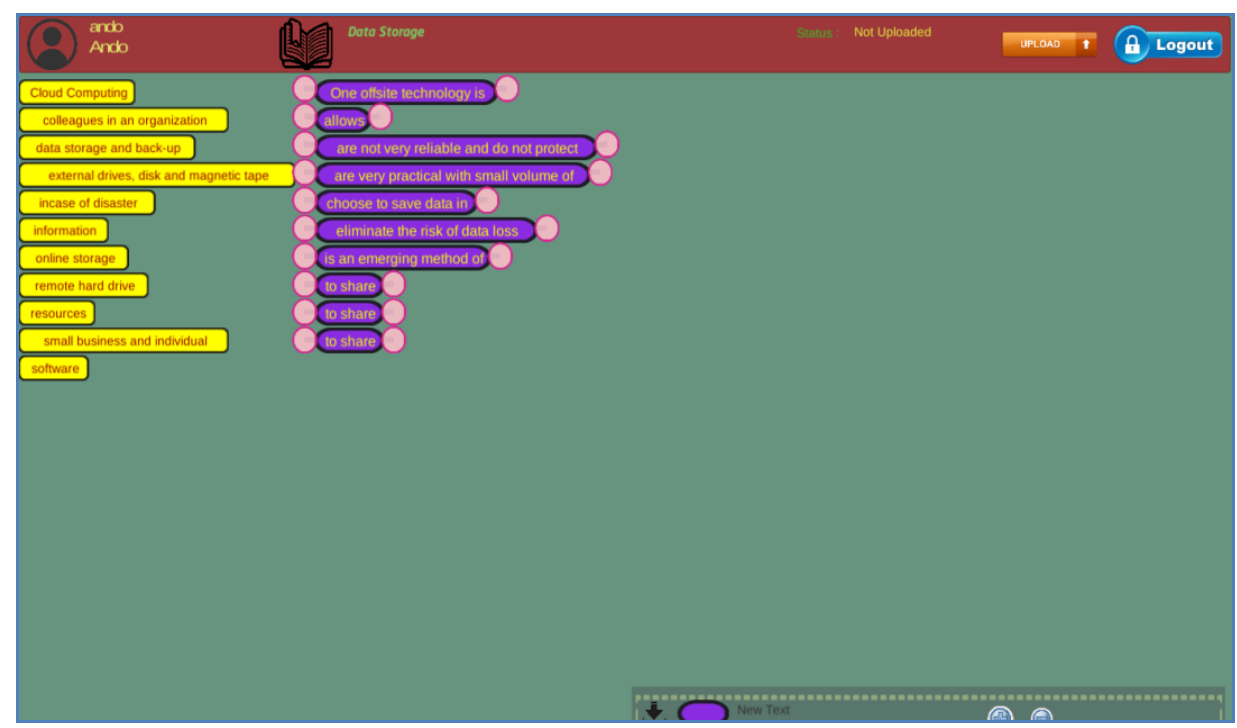

Figure 2. The display of the Nodes on the KB-Map before mapped by the students

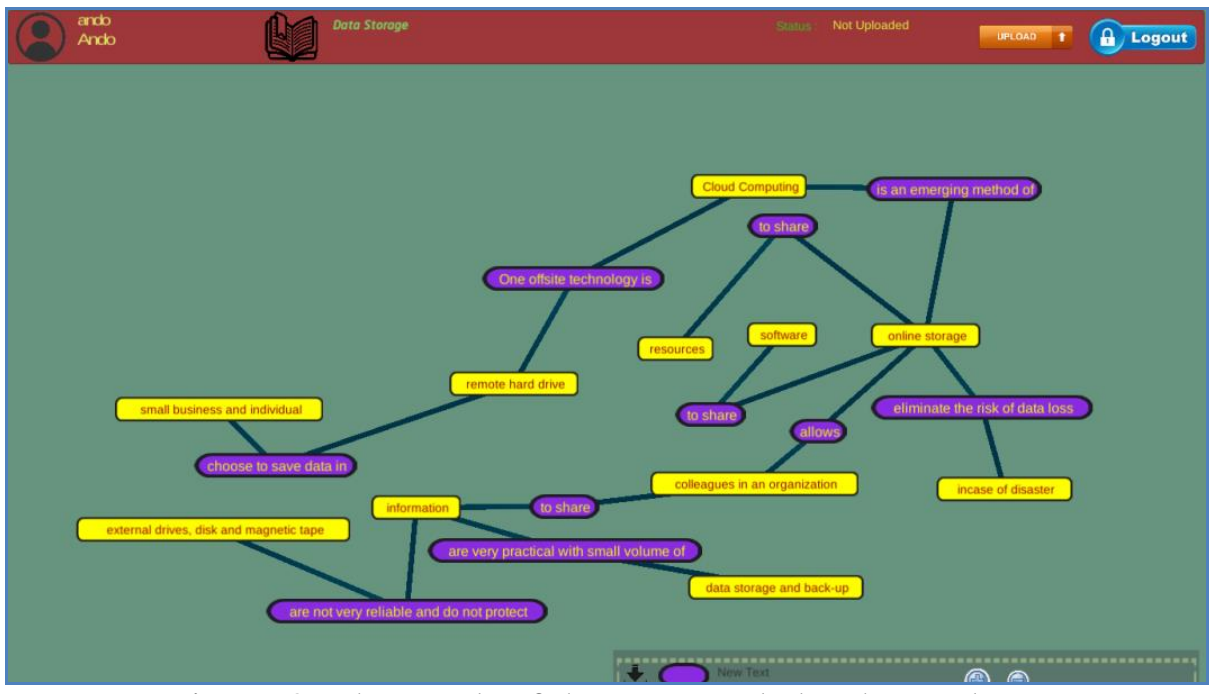

Figure 3. The result of the map made by the students

At the second meeting, the students were, like the previous meeting, asked to open the application http://kit-build.net:3012and $\log$ in. After that, they worked on the delay test, the reading questions was the same as those at the previous meeting, for 10 minutes. Then the score of the delay test was obtained, with an average of 74.23. After that, the students were given a review of what they had done and the obstacles they had faced and discussed the solution. Next, they were given a second text prepared. The second text had a difficulty level above the first text, even though it was still related to the IT field. They were asked to repeat the procedures being taught. The average reading test was 66.15 .

The third meeting began with giving a 10 minute delay test. The average result of this test was 60.76. Furthermore, the students were asked to fill out questionnaires regarding their perceptions about the application of this method to improve their reading skills. From the results of the open question given, it can be concluded that the average student believed that this method was interesting and could help them understand and remember the reading material, especially for students whose types were visual learning. Students who were reluctant to read also felt interested in reading because there were visual aids in the form of 
maps to better understand the contents of the reading. However, they also said that they often had difficulty making maps because they were not familiar with the time limits given and worked quickly, so they felt less relaxed in the class. Besides, they also suggested that the application design should be made more attractive. They also sometimes had some difficulties in making maps because there were several unfamiliar vocabulary words.

The data taken from pre-test, delay test 1 , test 2 , delay test 2 , and questionnaires were then analyzed to determine whether there were significant changes in students' reading ability. Even if it did not exist, it meant that the research would be carried out towards the second cycle.

From the results of the analysis of the four tests given, it can be concluded that the average score of test 1 (pre-test) and delay test 1 had exceeded the planned target. This was because the given text was familiar to the student because it had been discussed at the previous meeting. While in test 2 , the students were immediately given new texts without being discussed first.

As the students responded to the questionnaire above, they had difficulty in understanding the reading text and making a map as well because there were several unfamiliar and difficult vocabularies. Even though they were allowed to open a dictionary during the making of a map, the time limit given made them difficult, because as they conveyed to the questionnaire, they were not used to working quickly. However, the average result of test 2 slightly exceeded the criteria of success, which was 66.15. However, delay test 2 showed that the average of 60.77 did not exceed the criteria of success.

Based on the above reasons, the second phase was needed by revising the implementation phase (see Table 3), which was to provide information about the text to be read by giving questions related to the contents of the reading and explaining the unfamiliar vocabularies, but the time limit was fixed. The second cycle also consisted of 2 meetings.

Table 3. The revised research procedures

\begin{tabular}{|c|c|l|}
\hline Meeting & Time (in minutes) & \multicolumn{1}{c|}{ Teacher's and Students' Activities } \\
\hline \multirow{3}{*}{1} & 15 & Teacher gives Pre-teaching activities \\
\cline { 2 - 3 } & 10 & Students read a given text \\
\cline { 2 - 3 } & 20 & Students create maps while reading the text \\
\cline { 2 - 3 } 2 & 10 & Students do Reading Comprehension Test(test 3) \\
\hline & 10 & $\begin{array}{l}\text { Students do Delay test 3: re-do the previous Reading } \\
\text { Comprehension Test }\end{array}$ \\
\hline
\end{tabular}

The second cycle of the first meeting began with teacher's providing information about the text the students wouldbe read by conducting pre-teaching activities, namely by giving questions related to reading as a trigger in exploring students' previous knowledge of the topics discussed in the reading. This was done to link what students had known with the topics so that they would understand the contents of the reading. Besides, some difficult and new vocabularies were also explained first. The difficulty level of the text given was not much different from the text given in test 2 . Then students were asked to do the procedures again. Finally, the reading test was given and the average reading test was 68.46 . It meant that this result exceeded the criteria for success.

A week later, the second meeting of the second cycle began with the provision of delay test 3 for 10 minutes. The average result of this test was 63.08, which meant that this result did not exceed the criteria of success.

The results of the tests in the second cycle of this study were then analyzed again, and it can be concluded that there was an increase in the average score of test 3 compared to the test 
2 in the first cycle, as well as the delay test (see Table 3). The average score in test 3 also exceeds the predetermined success criteria, but for the score of delay test,three is not even though compared to delay test 2 in the first cycle, delay test 3 in the second cycle has increased. Test 2 and test 3 experienced different treatments at the beginning of the activity before students were asked to read the text. In test 3,they were given pre-teaching activities first by exploring student background knowledge by giving questions related to the text to be read. Besides, difficult words contained in the reading or text were also explained first. While in test 2, these two things were not done. This research should be continued in the third cycle or more, but due to time constraints (due to approaching the Semester Final Examination), it was stopped for further reporting stage.

Table 4. The average score of all the reading and delay tests (cycle 1 and 2)

\begin{tabular}{|c|c|c|c|c|c|c|c|}
\hline No. & Students' Name & Test 1 & Delay Test 1 & Test 2 & Delay Testz & Test 3 & Delay Test 3 \\
\hline 1 & & 90 & 80 & 70 & 70 & 70 & 60 \\
\hline 2 & & 80 & 70 & 60 & 50 & 70 & 60 \\
\hline 3 & & 100 & 90 & 60 & 50 & 80 & 70 \\
\hline 4 & & 80 & 80 & 60 & 40 & 80 & 70 \\
\hline 5 & & 70 & 70 & 80 & 70 & 100 & 90 \\
\hline 6 & & 50 & 40 & 50 & 40 & 60 & 50 \\
\hline 7 & & 90 & 90 & 70 & 70 & 80 & 80 \\
\hline 8 & & 80 & 60 & 60 & 70 & 60 & 50 \\
\hline 9 & & 90 & 80 & 60 & 80 & 70 & 60 \\
\hline 10 & & 80 & 80 & 80 & 70 & 60 & 50 \\
\hline 11 & & 80 & 70 & 90 & 70 & 90 & 90 \\
\hline 12 & & 60 & 50 & 60 & 60 & 60 & 50 \\
\hline 13 & & 80 & 80 & 80 & 70 & 80 & 80 \\
\hline 14 & & 80 & 70 & 90 & 70 & 60 & 70 \\
\hline 15 & & 80 & 80 & 70 & 70 & 70 & 60 \\
\hline 16 & & 90 & 80 & 70 & 50 & 70 & 70 \\
\hline 17 & & 90 & 90 & 50 & 40 & 80 & 70 \\
\hline 18 & & 60 & 50 & 30 & 40 & 40 & 40 \\
\hline 19 & & 80 & 70 & 50 & 30 & 60 & 50 \\
\hline 20 & & 90 & 70 & 40 & 40 & 40 & 40 \\
\hline 21 & & 60 & 80 & 60 & 80 & 60 & 60 \\
\hline 22 & & 100 & 90 & 60 & 60 & 70 & 60 \\
\hline 23 & & 90 & 80 & 90 & 70 & 90 & 80 \\
\hline 24 & & 90 & 90 & 80 & 70 & 50 & 50 \\
\hline 25 & & 80 & 80 & 80 & 80 & 90 & 90 \\
\hline 26 & & 80 & 60 & 70 & 70 & 40 & 40 \\
\hline & & & & & & & \\
\hline & Average Score & 80.769 & 74.23077 & 66.154 & 60.76923 & 68.462 & 63.07692 \\
\hline
\end{tabular}

From the data from the average test 2 and test 3, there was indeed a difference or an improvement in test 3 after different treatments were taken. However, to be more convincing, paired t-tests were carried out because it was assumed that these two tests were given on the same object but experienced different treatments (see Table 5).

Table 5. The results of paired t-tests

\begin{tabular}{|l|l|l|}
\hline & Test 2 & Test 3 \\
\hline Mean & 66.15384615 & 68.46153846 \\
\hline Variance & 232.6153846 & 253.5384615 \\
\hline Observation & 26 & 26 \\
\hline Pearson Correlation & 5.182016654 & \\
\hline \multicolumn{2}{|c|}{} \\
\hline Hypothesized Mean Difference & 0 \\
\hline Df & 250 \\
\hline t Stat & -0.768473279 \\
\hline
\end{tabular}


From the results of the analysis of the two tests, it can be concluded that even though the average obtained from test 2 and test 3 has improved and fulfills the criteria of success, the data above shows that the p-value declaring test 2 has no difference from test 3 as much as 0.44 . The statement that test 2 is different from test 3 is not acceptable; thus, it can be said that there is no significant difference between test 2 and test 3 since the $p$-value is more than 0.05 (Kadir: 2015).

Thus, from all the data above, it can be analyzed and interpreted as follow. The study was triggered by the importance of reading skills mastered by Information Technology Department students in understanding various kinds of learning resources such as e-books, journal articles, which are mostly written in English. Moreover, the students' low interest in reading caused an idea to implement a method, namely KB-Mapping. This method itself is adapted from the method presented by Alkhateeb et al. (2016) and Andoko, Hayashi, and Hirashima (2017). In this study, the KB Mapping application designed by Andoko was used and can be accessed at http://kit-build.net:3012.

Furthermore, this study is Classroom Action Research; therefore, the results of this study cannot be used as a generalization of a new theory about the use of $\mathrm{KB}$ mapping methods in improving student reading skills because the results of this study can only be applied to specified objects and the results may be very different when used on different research subjects. From the difference in average results, especially test 2 and test 3 , simply, it can be said that this study was successful in improving students' reading skills after different treatments were carried out in test 3 . This is because, in teaching reading, students should be given strategies that can help them understand a reading text.

In general, according to Hasan, et al., (2001) in Pujiono (Setyawan Pujiono, 2008)strategy is a careful plan regarding activities to achieve specific goals. Pringgawidagda (2002: 88) in Pujiono (2008) states that strategy is a method, technique, or tactic carried out by a person or group of people to achieve a predetermined goal. When associated with learning and teaching activities, strategies can be interpreted as general patterns of the activities of teachers and students in teaching and learning activities to achieve predetermined goals.

In particular, reading strategy is the use of a method, technique, tactic, or strategy in understanding a reading text. The application of reading strategies is needed, especially for language students as a second language or foreign language. A language student who already has the ability to read in his/her first language needs to improve the correct and effective reading strategy when reading a text in his/her second language(Brown, 2001). As quoted by Sulistyo (2011), Brown mentions several strategies that can be used which include bottom-up theory and top-down reading.

The bottom-up theory in reading states that the reader's understanding of the text is derived from the text itself. In other words, the reading process is done by the reader by identifying each element contained in the text starting from words composed of several letters to larger structures, namely phrases, sentences, and discourses or text or discourse. Understanding the meaning of the text is then carried out by combining the small elements of the language contained in a text one by one to form the overall meaning. Accordingly, the reader is a language code breaker in written text to find hidden meaning in a text (Sulistyo, 2011).

On the other hand, the top-down reading theory is intended that the reader's understanding of a text starts from the reader itself. When reading a text, the reader activates the knowledge he/she has stored in schemata (in the brain) to help him/her understand the 
meaning of the text. This is by the schemata theory, as quoted from Sulistyo (2011) which explains that information will be obtained, processed, compiled, and stored as a knowledge that will be activated when someone gets similar information when reading. If the information is useful, then a little more schemata will be needed to be added to the brain to be able to store new knowledge. Therefore, readers are called constructivists of meaning or builders of ideas.

Based on the above theories about reading and strategies, it can be inferred that those are very useful in improving reading skills and can have a better impact accompanied by making maps in the KB-Mapping method. Consequently, teachers should first introduce strategies in reading, including the making of semantic mapping, as mentioned by Sulistyo (2011) before applying the KB-Mapping method. So, when students are given this method, they will not be too difficult to understand the text and will increasingly understand and remember the contents of the text if they can create a map in the KB-Mapping application and do both the comprehension on the delay tests.

In answering the second question in the formulation of the problem of this study, which is to know the perceptions of students in the application of KB-Mapping, it can be said that this method got a positive response from students. This is based on the results of a questionnaire filled out by students who said that they felt their reading ability and motivation to read had improved and this method was interesting especially for those who had a type of visual learner. Besides, they also mentioned that their ability to remember also increased because when they read, they also made maps at the same time.

\section{CONCLUSION}

Overall, this study can be said to be successful when viewed from the average scoreof test 2 and test 3, where they meet the criteria of success, and there is an increasedscore between test 2 and test 3 and delay test 2 and delay test 3, ignoring paired $t$-test which showed that there was no significant difference between those two tests (because the results were 0.44 which, according to the statistic theories, was considered not significantly different). Besides, the students also respond positively to the application of this method and feel this method can improve the ability to read and remember the contents of the text or reading as well as their motivation.

To prove that the KB-Mapping method can improve reading skills, well-prepared planning is needed, such as debriefing students about reading strategies, especially the concept mapping and familiarizing them with a given reading text. Also, the students also need to be facilitated to improve their reading skills such as Self-Access Center (SAC) which promotes them to learn independently so that they can train themselves, especially their reading skills outside the classroom. Also, it is suggested that for further study not be in the form of Class Action Research, but another type of research whose results can be generalized into a theory that can show the effectiveness of this method in improving reading skills.

\section{REFERENCES}

Alkhateeb, M., Hayashi, Y., Rajab, T., \& Hirashima, T. (2016). Experimental use of kit-build concept map system to support reading comprehension of EFL in comparing with selective underlining strategy. International Journal of Advanced Computer Science and Applications, 7(4).

Andoko, B. S., Hayashi, Y., \& Hirashima, T. (2017). Analysis of the concept mapping style in EFL reading comprehension comparison between kit-build and scratch-build concept mapping from the viewpoint of the paragraph structure of the text. $20173 \mathrm{rd}$ 
International Conference on Science in Information Technology (ICSITech), 622-625. https://doi.org/10.1109/ICSITech.2017.8257188.

Brown, H. D. (2001). Teaching by principles: an interactive approach to language pedagogy (2nd ed). White Plains, NY: Longman.

GH Sulistyo. (2011). Reading for meaning. Malang: Pustaka Kaiswaran.

Kemmis, S. (Ed.). (1992). The action research planner (3. ed., reprint). Victoria: Deakin Univ.

Setyawan Pujiono, S. P. (2008). MAKALAH PPM: Metode K-W-L Dalam Pembelajaran Membaca Kritis. Retrieved from http://staffnew.uny.ac.id/upload/132318127/pengabdian/2.+PPM+Makalah+PPM++wat es+K-W-L.pdf.

Tajeddin, Z., \& Tabatabaei, S. (2016). Concept mapping as a reading strategy: Does it scaffold comprehension and recall. The Reading Matrix: An International Online Journal, 16(1), 194-208.

Zwaal, W., \& Otting, H. (2012). The Impact of Concept Mapping on the Process of Problembased Learning. Interdisciplinary Journal of Problem-Based Learning, 6(1). https://doi.org/10.7771/1541-5015.1314. 